\title{
Pacientes com síndrome de Turner atendidas em um serviço de genética clínica: por que o diagnóstico está sendo tão tardio?
}

\author{
Poli, J.H.Z.; Vogt, G.N.; Feltes, I.C.; Sampaio, V.O.; \\ Apresentador: Jefferson Henrique Zwir Poli
}

\section{Resumo}

Introdução: A síndrome de Turner (ST) é uma doença genética comum (observada em 1 para cada 2.500- 3.000 nascidos vivos do sexo feminino) caracterizada pela falta de um segundo cromossomo sexual normal. Clinicamente, as pacientes apresentam um fenótipo variável, muitas vezes até normal, com exceção da baixa estatura. Nosso objetivo foi verificar a prevalência, o motivo do encaminhamento e os achados citogenéticos de pacientes diagnosticadas com ST em nosso Serviço. Método: A amostra foi constituída de pacientes diagnosticadas no Serviço de Genética Clínica da Universidade Federal de Ciências da Saúde de Porto Alegre/Complexo Hospitalar Santa Casa de Porto Alegre, no período de janeiro de 1975 a junho de 2008. Uma análise retrospectiva foi realizada através de uma revisão sistemática dos prontuários médicos, com coleta de dados referentes a seus achados clínicos e citogenéticos. Resultados: Dos 9.773 pacientes avaliados pelo Serviço neste período, 117 (1\%) foram diagnosticadas com ST. A idade no momento da primeira avaliação variou de 1 dia de vida a 59 anos. Dezesseis (14\%) se encontravam no primeiro ano de vida, 20 (17\%) possuíam idade entre 1 e 10 anos, 39 (33\%) entre 10 e 16 anos e 42 (36\%) acima dos 16 anos. A maior parte das pacientes já veio encaminhada por suspeita clínica de ST (63\%). Cerca de metade delas (54\%) foi encaminhada pela Endocrinologia, $25 \%$ pela Pediatria, $9 \%$ pela Ginecologia e $12 \%$ por outras especialidades. Quanto à análise cromossômica, o cariótipo 45, X foi o preponderante $(\mathrm{N}=55)$. As demais pacientes apresentavam mosaicismo $(\mathrm{N}=43)$ e/ou alterações cromossômicas estruturais envolvendo o cromossomo $\mathrm{X}(\mathrm{N}=48)$. Conclusões: $\mathrm{O}$ percentual de pacientes com ST encontrada em nosso estudo (1\%) reforça a importância do reconhecimento desta doença na prática clínica diária. A frequência dos achados citogenéticos de nossa amostra foi concordante com a literatura. Provavelmente devido à variabilidade fenotípica, um percentual significativo das pacientes foi identificado tardiamente, o que apresenta implicação direta no seu manejo e tratamento.

\section{Referência:}

Poli, J.H.Z.; Vogt, G.N.; Feltes, I.C.; Sampaio, V.O.;. Pacientes com síndrome de Turner atendidas em um serviço de genética clínica: por que o diagnóstico está sendo tão tardio?. In: II Congresso Brasileiro de Medicina Hospitalar - II CBMH [= Blucher Medical Proceedings, vol.1, num.5] São Paulo: Editora Blucher, 2014. p.78

DOI 10.5151/medpro-II-cbmh-075 